\title{
Fetomaternal outcome in breech delivery
}

\author{
Bhavesh B. Airao, Vishal M. Sharma*, Ravi A. Zala, Vimal Vasava
}

Department of Obstetrics and Gynecology, C. U. Shah Medical College and Hospital, Surendranagar, Gujarat, India

Received: 15 April 2018

Accepted: 08 May 2018

\section{*Correspondence:}

Dr. Vishal M. Sharma,

E-mail: sharmavsh1969@gmail.com

Copyright: ( ) the author(s), publisher and licensee Medip Academy. This is an open-access article distributed under the terms of the Creative Commons Attribution Non-Commercial License, which permits unrestricted non-commercial use, distribution, and reproduction in any medium, provided the original work is properly cited.

\begin{abstract}
Background: Breech Presentation is the commonest of all malpresentations. Vaginal delivery of the breech presentations at term is associated with a much higher perinatal mortality and morbidity than that of vertex presentation. The objectives of the present study are to know the common causes leading to breech presentation. Further, to compare the different management protocols and outcome in different types of breech presentation. Also, to know the perinatal morbidity and mortality associated with different types of breech presentation nd comparison of perinatal morbidity and mortality with vaginal delivery against cesarean section.

Methods: This is a retrospective study of randomized 100 cases of pregnant women in labour with breech presentations after 28 weeks or more attending C U Shah Medical College, Surendranagar, over a period of May 2012 to April 2014.

Results: Out of 100 patients breech presentation was more common in booked patients and multigravida. In primi and multigravidae patients, caesarean delivery was more compared to assisted breech delivery. Perinatal outcome was good in majority of the patients in both extended and complete breech with an incidence of $94 \%$ and $88 \%$ respectively. perinatal outcome was good in caesarean section with $100 \%$ compared to assisted breech delivery $93 \%$.

Conclusions: The balanced decision about the mode of delivery on a case by case basis as well as conduct, training and regular drills of assisted breech delivery will go a long way to optimize the outcome of breech presentation like ours. Delivery of breech fetus when labor and delivery is supervised and or conducted by experienced obstetrician lowers maternal morbidity, neonatal morbidity and mortality.
\end{abstract}

Keywords: Breech presentation, Caesarean section Fetomaternal outcome, Maternal morbidity

\section{INTRODUCTION}

Breech Presentation is the commonest of all malpresentations. Vaginal delivery of the breech presentations at term is associated with a much higher perinatal mortality and morbidity than that of vertex presentation. An attempt to reduce the fetal hazards inherent in a vaginal breech delivery has resulted in a high caesarean section rate which has approached 90$95 \%$ in some centers. Breech presentation is the $3^{\text {rd }}$ important indication which has led to higher caesarean section rates in recent times all over the world ${ }^{1}$. Although
CS drastically reduces the perinatal mortality associated with breech delivery, it has not eliminated the associated fetal and maternal morbidity; in fact, it has been quoted that the competency of any obstetric unit is inversely proportional to the perinatal mortality of breech deliveries conducted in that unit. Therefore, any change or improvement in the mode or technique of breech delivery should aim at improving the perinatal outcome and also at keeping the maternal morbidity and mortality rates low. It is the fetus who suffers the most rather than the mother. So, the fetal outcome decides the merit of the particular method for the management of labour in breech 
presentation. So, this study was conducted with the aim of proving that vaginal breech delivery is definitely a choice for many patients having favorable factors avoiding unnecessary operative interventions.

Unfortunately, the number of obstetricians able to conduct the vaginal breech delivery is declining quite fast. If the trend continues, what will happen when a woman with breech presentation at term gets admitted in advanced labor at a center where cesarean section cannot be performed urgently and the obstetrician present has never conducted a vaginal breech delivery? It will indeed be a very sad day for our specialty.

As the controversy continues, repeated evaluations and reviews of management in this subset of women are needed. The present study was conducted with an objective to optimize the perinatal outcome, while keeping the art of conducting and training vaginal breech deliveries alive.

\section{METHODS}

This is a retrospective study of randomized 100 cases of pregnant women in labour with breech presentations after 28 weeks or more attended Department of Obstetrics and Gynaecology, C U Shah Medical College, Surendranagar, during the period from May 2012 to April 2014.

Maternal and perinatal outcome were studied in 100 cases of pregnant women in labour with breech presentation including those who delivered vaginally, those who delivered abdominally, and data is presented here, which were analyzed, and conclusion drawn, presented in tabular form with explanatory notes below each table.

A detailed study of all cases was done. Each patient was asked a detailed history on admission along with obstetric history, history regarding antenatal care, number of visits, etc. was elicited. History of previous breech delivery and previous abdominal delivery with its indications were also enquired. A careful general examination and systemic examination were carried out in all patients including height and weight. Per abdominal examination included measurement of fundal height, abdominal girth, presentation, position, engagement of presenting part, location of fetal heart sound and uterine contractions. Per vaginal examination was done to determine position, effacement and dilatation of cervix, presence of bag of membranes, presenting part and its station and adequacy of the pelvis. Routine investigations like Haemoglobin and Urine for albumin, sugar and microscopy were done in all patients. Ultrasound examination was done. Patient underwent ultra-sound examination to confirm single foetus, presentation, type of breech, amniotic fluid volume, location of placenta, estimated foetal weight, any obvious congenital anomaly and position of the foetal spine. The USG examination was considered abnormal if there was Oligohyramnios, placenta praevia, suspected foetal anomaly or an estimated foetal weight less than tenth percentile for gestational age. Then, according to patient's condition and associated complications other investigations were carried out as indicated. The decision of vaginal or cesarean section was made according to protocol.

\section{Selection criteria for breech vaginal delivery}

- $\quad$ estimated baby weight 2.5 to $3.5 \mathrm{~kg}$

- frank and complete breech

- normal progress of labour

- absence of fetal distress

- absence of hyperextension of head

- clinical evidence of normal pelvis.

\section{Selection criteria for cesarean section}

- footling presentation

- fetopelvic disproportion

- fetal distress

- uterine anomaly

- primi gravida

- $\quad$ estimated baby weight more than $3.5 \mathrm{~kg}$.

All babies were immediately resuscitated by pediatrician. The babies were examined for any marks of injury or congenital anomalies. The APAGAR score at 1 minute and 5 minutes were determined. In case of neonatal death, the cause of death was determined. Both mother and baby were followed up daily in the ward till discharge. Maternal and neonatal morbidity were noted. Any specific treatment given to newborn recorded. On discharge, all patients were called for follow up in the postnatal clinic till one month when the mother and baby were examined and appropriate advice regarding contraception was given.

\section{RESULTS}

In this study total numbers of 100 cases with breech presentation in labour were selected on randomized basis. Maternal and Perinatal outcome was studied either delivered vaginally or abdominally. In present study, incidence of registered cases 55, was more than that of emergency cases, which was 45. Most of the booked cases had attended antenatal OPD regularly and had undergone required investigations. Out of 100 cases studied 47 were primigravidae with breech presentation giving an incidence of $47 \%$ and 32 were Para 2 giving an incidence of $32 \%, 14$ were Para3 with an incidence of $14 \%$. Most of the patients fall in the group of 21-25 years with an incidence of $51 \%$, this age group represents an in general reproductive age group of our country. In this study, only 1 patient had recurrence of breech presentation. majority of the patients were more than 37 weeks in both, primigravidae with an incidence of $92 \%$ and Multigravida with an incidence of $98 \%$. incidence of extended breech was more $(68 \%)$ than that of complete breech $(32 \%)$ which favors early engagement and less 
chance of cord prolapse. Among the primigravidae, extended breech was more common with an overall incidence of $66 \%$, whereas among the Multigravida patients complete breech was more common with an overall incidence of $63 \%$. Among the 47 cases of primigravidae, majority of the cases had caesarean section with an incidence of $73 \%$, compared to Hannah et al which had $71.6 \%$ and Kimbrecy et al which had $79 \%$ and Min su et al which had 70.02\%.,7,9 And 12 cases had assisted breech delivery with an incidence of $27 \%$, compared to Hannah et al which had $28.4 \%$ and Kimbrecy et al which had 21\%.,7 Among the Multigravida majority had assisted breech delivery with an incidence of $64 \%$ and caesarean section an incidence of $36 \%$. In frank breech, $47.06 \%$ required caesarean section, while $52.94 \%$ delivered vaginally. In complete breech, $68.75 \%$ required caesarean section, while $31.25 \%$ delivered vaginally. most common indication for LSCS among the primigravidae was breech presentation with CPD (29 cases with an incidence of $83 \%$ ). CPD was diagnosed on the basis of clinical pelvimetry. 5 cases had fetal distress with an incidence of $13.5 \%$. Fetal distress was diagnosed based on fetal bradycardia and irregular FHS. One case was of elderly primigravidae, who had taken treatment for infertility, with breech presentation with an incidence of $3.5 \%$. Previous LSCS and fetal distress were most common indications for caesarean section among the Multigravida with 6 cases and 4 cases giving an incidence of $32 \%$ and $21.5 \%$ respectively. 3 cases had previous two LSCS with an incidence of $16 \%$. Other indications were complete breech, large baby and placenta previa with 2 cases each. In this study, out of 100 cases, 9 patients had history of previous caesarean section. All of them were delivered by caesarean section, 7 patients electively and 2 patients in emergency. No patient with history of previous CS delivered vaginally. Thus, trial of scar was not given amongst women with breech presentation, irrespective of cervical dilatation. perinatal outcome was good in majority of the patients in both extended and complete breech with an incidence of $94 \%$ and $88 \%$ respectively. Unsatisfactory outcome was more common in complete breech with an incidence of $6 \%$ because of low APGAR, LBW and IUGR babies. All such babies were shifted to NICU. Two perinatal deaths were as a result of intrapartum asphyxia due to difficulty in delivery of the after coming head, one in complete breech and one in extended breech, both cases came in second stage due to late referral and undiagnosed breech at the peripheral health centers. One baby died of RDS due to prematurity with birth weight of $1.7 \mathrm{~kg}$., while the perinatal outcome was good in LSCS with an incidence of $100 \%$. Three cases in assisted breech delivery and three cases in caesarean section had low APGAR at the end of five minutes. All the six babies were shifted to NICU. Out of which 3 babies died, 2 because of birth asphyxia and 1 because of prematurity. Rest 3 babies on recovery were shifted to mother's bedside. It was observed that the perinatal outcome was more unsatisfactory when the birth weight was $1.5-2 \mathrm{kgs}$ with an incidence of $42 \%(35+8)$.

\section{DISCUSSION}

In this study, randomly selected 100 cases of pregnant women with breech presentation who attended the labour room of C U Shah medical college, Surendranagar have been studied during the period of May 2012 to April 2014. Detailed analysis has been done and results have been compared with the statistics available from Indian authors and other authors around the world (Table 1). ${ }^{2-5}$

Table 1: Incidence and parity of breech.

\begin{tabular}{|llll|}
\hline Authors & Year & $\begin{array}{l}\text { Primi- } \\
\text { gravidae } \\
(\%)\end{array}$ & $\begin{array}{l}\text { Multi- } \\
\text { gravidae } \\
(\%)\end{array}$ \\
\hline Nahid et al & 2000 & 34 & 66 \\
\hline $\begin{array}{l}\text { Bushra Rauf } \\
\text { et al }\end{array}$ & 2001 & 24.1 & 75.9 \\
\hline $\begin{array}{l}\text { Igwegbe et al } \\
\text { Singh Abha } \\
\text { et al }\end{array}$ & 2010 & 38.5 & 61.5 \\
\hline Present study & 2012 & 40.4 & 59.6 \\
\hline
\end{tabular}

Present study correlated well with other studies which too showed higher incidence of breech presentation in Multigravida than in primigravidae. This is probably because of relative low tone of uterine musculature in multigravida favouring malrotation and subsequent breech presentation.

\section{Table 2: Incidence of breech according to the age of patient.}

\begin{tabular}{|llll|}
$\begin{array}{l}\text { Age in } \\
\text { years }\end{array}$ & $\begin{array}{l}\text { Singh A et } \\
\text { al }\end{array}$ & $\begin{array}{l}\text { Igwegbe et } \\
\text { al }\end{array}$ & $\begin{array}{l}\text { Present } \\
\text { study }\end{array}$ \\
\hline$<20$ & $15.2 \%$ & $19.6 \%$ & $20 \%$ \\
\hline $21-25$ & $47.4 \%$ & $46.2 \%$ & $51 \%$ \\
\hline $26-30$ & $16.6 \%$ & $27.3 \%$ & $26 \%$ \\
\hline$>31$ & $20.8 \%$ & $6.9 \%$ & $3 \%$ \\
\hline
\end{tabular}

Table 3: Incidence of type of breech

\begin{tabular}{|lllll|}
\hline Authors & Year & Complete & Extended & Footling \\
\hline $\begin{array}{l}\text { Rani U } \\
\text { et al }\end{array}$ & 1993 & $27 \%$ & $49 \%$ & $24 \%$ \\
\hline Shalini G & 1999 & $48 \%$ & $46 \%$ & $6 \%$ \\
\hline Razak AH & 2007 & $32 \%$ & $67 \%$ & $1 \%$ \\
\hline $\begin{array}{l}\text { Singh A } \\
\text { et al }\end{array}$ & 2012 & $34.7 \%$ & $55.5 \%$ & $9.8 \%$ \\
\hline $\begin{array}{l}\text { Present } \\
\text { study }\end{array}$ & $2012-$ & $32 \%$ & $68 \%$ & $0 \%$ \\
\hline
\end{tabular}

Present study correlates with the study done by other authors; incidence of breech is higher among the age group of 21-25 years, as in India the age group of women who conceive fall in this group; this is a bit early than the trends observed amongst Western nations. The only difference observed between our study and the African study conducted by Igwegbe and colleges is in the age group of $>31$ years in which the incidence was a bit 
higher (6.9\%) as compared to present study (3\%). This is possibly because of the fact that in Indian women generally family life is completed by this age group due to early marriage and early age at first pregnancy (Table 2). ${ }^{4,6}$

As evident from Table 3, present study correlates with previous studies by other authors, it favors incidence of extended (frank) breech more than complete breech with a rate of $68 \%$ and $32 \%$ respectively. ${ }^{6-9}$ This is most probably because of a favorable engaging diameter in extended breech (bistrochanteric) and less space occupied by the narrow lower pole.

Table 4: Incidence of mode of delivery.

\begin{tabular}{|llll|}
\hline Authors & $\begin{array}{l}\text { Year of } \\
\text { study }\end{array}$ & $\begin{array}{l}\text { Vaginal } \\
\text { delivery }(\%)\end{array}$ & CS (\%) \\
\hline Hannah et al & 2000 & 33.2 & 66.7 \\
\hline Gilbert et al & 2003 & 4.91 & 95.1 \\
\hline Jukka et al & 2003 & 46.1 & 53.9 \\
\hline Bassaw et al & 2004 & 54.3 & 45.7 \\
\hline Bushra et al & 2004 & 55.8 & 44.2 \\
\hline Abasiatai et al & 2004 & 69.3 & 30.7 \\
\hline Goffinet et al & 2006 & 22.2 & 77.8 \\
\hline Singh A et al & 2012 & 42.6 & 57.3 \\
\hline Present study & $2012-$ & 46 & 54 \\
\hline
\end{tabular}

A positive correlation was observed with previous studies by other authors, that in majority of the studies, caesarean section was more common as a mode of delivery than vaginal route, in breech presentation; but the incidence should not be that low as observed in a few studies depicted in Table $4.6,10-15$

Table 5: Incidence of mode of delivery and perinatal outcome.

\begin{tabular}{|llllll|}
\hline Authors & Year & $\begin{array}{l}\text { Assisted } \\
\text { breech } \\
\text { delivery } \\
\%\end{array}$ & $\begin{array}{l}\text { PNM } \\
\%\end{array}$ & $\begin{array}{l}\text { LSCS } \\
\%\end{array}$ & $\begin{array}{l}\% \\
\%\end{array}$ \\
\hline $\begin{array}{l}\text { Patwardhan } \\
\text { M et al }\end{array}$ & 1990 & 75 & 27 & 25 & 1 \\
\hline $\begin{array}{l}\text { Shalini G } \\
\text { Singh A }\end{array}$ & 1999 & 62 & 26 & 38 & 2.6 \\
et al & 2012 & 43 & 3 & 57 & 1 \\
\hline $\begin{array}{l}\text { Jukka } \\
\text { et al }\end{array}$ & 2003 & 46 & 1.2 & 54 & 0.5 \\
$\begin{array}{l}\text { Present } \\
\text { study }\end{array}$ & $\begin{array}{l}2012 \\
-\end{array}$ & 46 & 11.54 & 54 & 0 \\
\hline
\end{tabular}

Present study correlates with the study done by other authors, as it shows perinatal mortality is high in assisted breech delivery as compared to caesarean section; but the rate of perinatal morbidity and mortality can be reduced by proper use of various maneuvers and development of the "art" of proficient breech delivery (Table 5). ${ }^{6,8,17,18}$
According to the Table 6, compared to other series, present study has low perinatal mortality with breech presentation. This was attributed to the availability of qualified and proficient obstetricians round the clock to manage patients with malpresentations, as well as, the facility of intensive neonatal care available at our centre in the form of incubator, warmer, NICU and the presence of competent paediatricians in the labour room at the time of breech delivery. ${ }^{4,6,9,17-19}$

Table 6: Incidence of overall perinatal mortality breech.

\begin{tabular}{|lll|}
\hline Authors & Year & PNM \% \\
\hline Susanne et al & 1998 & 4.3 \\
\hline Fawole et al & 2001 & 6.25 \\
\hline Giuliani et al & 2002 & 2.8 \\
\hline Orji et al & 2003 & 3.2 \\
\hline Igwegbe et al & 2010 & 5 \\
\hline Singh Abha et al & 2012 & 19.2 \\
\hline Present study & $2012-2014$ & 3 \\
\hline
\end{tabular}

Table 7: Statistical correlation with type of breech delivery and its outcome.

\begin{tabular}{|llll|}
$\begin{array}{l}\text { Type of } \\
\text { breech }\end{array}$ & $\begin{array}{l}\text { Vaginal } \\
\text { delivery } \\
(46)\end{array}$ & $\begin{array}{l}\text { Cesarean } \\
\text { section }(54)\end{array}$ & $\begin{array}{l}\text { Statistical } \\
\text { Values }\end{array}$ \\
\hline Frank (68) & 36 & 32 & $\begin{array}{l}x \times 2=4.122 \\
\mathrm{df}=1\end{array}$ \\
$\begin{array}{l}\text { Complete } \\
(32)\end{array}$ & 10 & 22 & $\begin{array}{l}\mathrm{p}<0.05 \\
(0.0423)\end{array}$ \\
\hline
\end{tabular}

Chi-square value determined by epi-info software.

Table 7 shows the probability of vaginal or caesarean delivery corresponding to the type of breech presentation. Here in this study chi-square and paired t-test was applied. And the results showed that with degree of freedom $(\mathrm{df})=1$ the results of chi square test were showing $p$ value of $<0.05$ which means there is a significant statistical association between these two groups. So, in cases of frank breech presentation irrespective of gravidity, trial of vaginal delivery should be given.

Table 8: Statistical study for correlation between parity and mode of delivery.

\begin{tabular}{|lll|l|}
$\begin{array}{l}\text { Mode of } \\
\text { delivery }\end{array}$ & $\begin{array}{l}\text { Primi- } \\
\text { gravidae }\end{array}$ & $\begin{array}{l}\text { Multi- } \\
\text { gravidae }\end{array}$ & $\begin{array}{l}\text { Statistical } \\
\text { analysis }\end{array}$ \\
$\begin{array}{l}\text { Vaginal } \\
\text { delivery }\end{array}$ & 12 & 34 & $\begin{array}{l}x x^{2}=13.442, \\
\mathrm{df}=1,\end{array}$ \\
Caesarean & 35 & 19 & $\begin{array}{l}\mathrm{p}<0.05 \\
(0.0002)\end{array}$ \\
\hline
\end{tabular}

Chi-square value determined by medical software.

As clearly mentioned in the Table 8 , when chi square test was applied for the Table 8 , it showed that the value of $x^{2}$ $=13.442$ with $\mathrm{df}=1$ and $\mathrm{p}$ value turned out to be $<0.05$ (0.0002), thus signifying statistical difference between 
two groups. So, multigravida is more commonly associated with vaginal delivery. So, patients with breech presentation in labour should be given trial especially if they are multigravida.

Table 9: Statistical study for comparison between type of breech and perinatal outcome.

\begin{tabular}{|llllll|}
\hline $\begin{array}{l}\text { Type of } \\
\text { Breech }\end{array}$ & $\begin{array}{l}\text { No of } \\
\text { Cases }\end{array}$ & \multicolumn{3}{|c|}{ Perinatal outcome } & $\begin{array}{l}\text { Statistical } \\
\text { study }\end{array}$ \\
Gow & $\begin{array}{l}\text { Low } \\
\text { Apgar }\end{array}$ & Died & $\begin{array}{l}x x^{2} \\
=1.725,\end{array}$ \\
Extended & 68 & 63 & 4 & 1 & $\begin{array}{l}\mathrm{df}=2, \\
\mathrm{p}>0.05 \\
(0.4221)\end{array}$ \\
\hline
\end{tabular}

Chi-square value determined by medical software.

As depicted in the Table 9, when chi-square test was applied to this table value of $x x^{2}=1.725$ with degree of freedom (df) is 2 and $\mathrm{p}$ value turned out to be $>0.05$ (0.4221). So, this suggests that although visually seems that perinatal outcome is good in extended breech, statistically it is not significant. So, whatever may be the type of presentation in breech, perinatal prognosis is almost similar in all types irrespective of method of termination of pregnancy.

\section{CONCLUSION}

In present study it was clearly observed that there was $0 \%$ perinatal mortality considering both elective and emergency caesarean section when compared to vaginal breech delivery; more specifically risk is lowest with caesarean during early labor.

Caesarean section decreases the risk of adverse perinatal outcome due to both problems of labour and problems of delivery for the singleton fetus in breech presentation at term compared with vaginal delivery; however, this difference is not much when confounding factors like prematurity and intrauterine fetal distress are adjusted. And caesarean is not always a safe, feasible and easy option for all patients, for all the institutions and every time when it comes to developing countries like of present study.

It was also noted that vaginal breech delivery in Multigravida women has good perinatal outcome than vaginal breech delivery in primigravidae women. So in multigravida patients without any associated obstetric complications except for the malpresentation with good uterine contractions and active labour, vaginal delivery surely merits high than caesarean. And in primigravidae also if pelvis is adequate, patient in active labour, favorable type of breech, reassuring fetal condition and good maternal bearing down, vaginal delivery surely should be tried if setup is ready for emergency operative procedure if required and qualified practitioner is there to conduct the delivery having technical skills necessary for vaginal breech delivery and knowledge of various maneuvers required for it.

But there are suggestions that with active involvement of experienced obstetricians and applying appropriate management protocols, vaginal breech delivery can achieve comparable safety for the infant with caesarean section.

There is still a place for vaginal breech delivery in selected cases of breech presentations more so in Multigravida women.

When the results of present study were compared with appropriate statistical analysis it showed that frank breech was more commonly associated with vaginal delivery than complete breech for reasons which are obvious. Also, multigravida is more prone for vaginal delivery. And above all whatever may be the type of presentation or parity status of the patient, perinatal outcome was not statistically significant in this study irrespective of mode of termination either vaginal or caesarean.

In countries where the majority of caesarean sections for breech presentation are done in emergency, a trial of vaginal delivery yields comparable results especially for those patients who are having frank breech presentation and are multigravida. But here a special mention needs to be made that, whenever and wherever, a trial of vaginal breech delivery is offered, every arrangement should be made for an emergency cesarean section in cases of failure since in breech presentation, fetal weight estimation is not always accurate, and cord prolapse and fetal distress are not always predictable.

Therefore, it is concluded that the balanced decision about the mode of delivery on a case by case basis as well as conduct, training and regular drills of assisted breech delivery will go a long way to optimize the outcome of breech presentation like present study.

Funding: No funding sources

Conflict of interest: None declared

Ethical approval: The study was approved by the Institutional Ethics Committee

\section{REFERENCES}

1. Studd J. Pioneers in obstetrics and gynaecology 1: William Smellie. The Diplomate.1994;1:153-4.

2. Nahid F. Outcome of singleton term breech cases in the pretext of mode of delivery. J Pak Med Assoc. 2000; 50(3): 81-5.

3. Rauf B, Ayub T. Maternal and perinatal outcome in term singleton breech presentation. J Postgraduate Medical Institute (Peshawar-Pakistan). 2011 20;18(3).

4. Igwegbe AO, Monago EN, Ugboaja JO. Caesarean versus Vaginal Delivery for Term Breech 
Presentation: a comparative analysis. Afr J Biomed Res. 2010;13(1):15-8.

5. Irion O, Hirsbrunner Almagbaly $\mathrm{P}$, Morabia A. Planned vaginal delivery versus elective caesarean section: a study of 705 singleton term breech presentations. BJOG. Int $\mathrm{J}$ Obst Gynaecol. 1998;105(7):710-7.

6. Singh A, Mishra N, Dewangan R. Delivery in breech presentation: The decision making. $\mathrm{J}$ of Obstet Gynaecol India. 2012;62(4):4015.

7. Weiner CP. Vaginal breech delivery in the 1990s. Clin Obstet Gynecol. 1992;35(3):559-69.

8. Shalini VP. Outcome of labour in pregnancy with breech. NHL Med Col. 1999.

9. Albrechtsen S, Rasmussen S, Dalaker K, Irgens LM. Perinatal mortality in breech presentation sibships. Obstet Gynecol. 1998;92(5):775-80.

10. Hannah ME, Hannah WJ. Planned caesarean section versus planned vaginal birth for breech presentation at birth: a Randomized multicentric trial. TBT collaborative group. Lancet. 2000; 356 (9239):137583.

11. Gilbert WM, Hicks SM. Vaginal versus caesarean delivery for breech presentation in California: a population based study. Obstet Gynaecol. 2003;102(5):911-7.

12. Uotila J, Tuimala R, Kirkinen P. Good perinatal outcome in selective vaginal breech delivery at term. Acta Obstet Gynaecol Scand. 2005;84(6):578-83.

13. Bassaw B, Rampersad N, Roopnarinesingh S, Sirjusingh A. Correlation of fetal outcome with mode of delivery for breech presentation. J Obst Gynaecol. 2004;24(3):254-8.

14. Abasiattai AM, Etuk SJ, Asuquo EE, Iklaki CO. Perinatal outcome following singleton vaginal breech delivery in the University of Calabar Teaching Hospital, Calabar: a 10-year review. Mary Slessor J Med. 2004;4(1):81-5.

15. Goffinet F, Carayol M, Foidart JM, Alexander S, Uzan S, Subtil D, Bréart G. is planned vaginal breech delivery for breech presentation still an option?. Am J Obstet Gynaecol. 2006;194(4):1002-11.

16. Gilbert WM, Hicks SM. Vaginal versus caesarean delivery for breech presentation in California: a population based study. Obstet Gynaecol. 2003;102(5):911-7.

17. Fawole AO, Adeyemi AS, Adewole IF, Omigbodun AO. A ten-year review of breech deliveries at Ibadan. Afr J Med Med Sci. 2001;30(1-2):87-90.

18. Giuliani A, Schöll WM, Basver A, Tamussino KF. Mode of delivery and outcome of 699 term singleton breech deliveries at a single center. Am J Obst Gynecol. 2002;187(6):1694-8.

19. Orji EO, Ajenifuja KO. Planned vaginal delivery versus caesarean section for breech presentation in Ile-Ife, Nigeria. East African Medi J. 2003;80(11):589-91.

Cite this article as: Airao B, Sharma VM, Zala RA, Vasava V. Fetomaternal outcome in breech delivery. Int J Reprod Contracept Obstet Gynecol 2018;7:2480-5. 